Bond University

Research Repository

\title{
Open-plan office noise is stressful: multimodal stress detection in a simulated work environment
}

Sander, Elizabeth (Libby) J.; Marques, Cecelia; Birt, James; Stead, Matthew; Baumann, Oliver

Published in:

Journal of Management and Organization

DOI:

10.1017/jmo.2021.17

Licence:

Other

Link to output in Bond University research repository.

Recommended citation(APA):

Sander, E. J., Marques, C., Birt, J., Stead, M., \& Baumann, O. (2021). Open-plan office noise is stressful: multimodal stress detection in a simulated work environment. Journal of Management and Organization, 27(6), 1021-1037. https://doi.org/10.1017/jmo.2021.17

\section{General rights}

Copyright and moral rights for the publications made accessible in the public portal are retained by the authors and/or other copyright owners and it is a condition of accessing publications that users recognise and abide by the legal requirements associated with these rights.

For more information, or if you believe that this document breaches copyright, please contact the Bond University research repository coordinator 


\title{
Open plan office noise is stressful: Multimodal stress detection in a simulated \\ work environment
}

\begin{abstract}
Covid-induced changes in the workplace present a timely opportunity for HRM practitioners to consider and remediate the deleterious effects of noise, a commonly cited complaint of employees working in open-plan office environments. While self-reports suggest that open plan office noise is perceived as a stressor, there is little experimental research comprehensively investigating the effects of noise on employees in terms of their cognitive performance, physiological indicators of stress, and affect. Employing a simulated office setting, we compared the effects of a typical open plan office auditory environment to a quieter private office auditory environment on a range of objective and subjective measures of wellbeing and performance. While open plan office noise did not reduce immediate cognitive task performance compared to the quieter environment, it did reduce psychological well-being as evidenced by self-reports of mood, facial expressions of emotion, and physiological indicators of stress in the form of heartrate and skin conductivity. Our research highlights the importance of using a multimodal approach to assess the impact of workplace stressors such as noise. Such an approach will allow HR practitioners to make data-driven recommendations about the design and modification of workspaces to minimise negative effects and support employee well-being.
\end{abstract}


The coronavirus pandemic caused a sudden and substantial shift in the location of work, with entire workforces moving from working in communal office settings to working-fromhome virtually overnight. As employees begin to return to the office, possibly in conjunction with working from home part of the time, organizations are reconsidering their options for providing healthy and facilitating workspaces. Potentially reduced employee density may offer the opportunity to redesign workspaces and overcome known problems with the dominant prepandemic design, the open plan office. Prior to the pandemic, $70 \%$ of office-based employees worked in open plan offices (OPO) (Konnikova, 2014) with many employees sharing common work areas with few walls and little distance between desks (Ayoko \& Ashkanasy, 2020; Bodin Danielsson and Bodin, 2009; Oldham and Rotchford, 1983). Occupant complaints about this design are rife (e.g., Davis, Leach \& Clegg, 2007; Kim \& de Dear, 2013), particularly when compared to enclosed private or semi-private offices.

Open plan offices and other workspace designs have been studied using the concept of Indoor Environmental Quality (IEQ). This is often assessed by occupant reports their satisfaction with features of the workspace including thermal comfort, air quality, visual and acoustic privacy, noise level, furnishings, lighting, and layout. The most commonly used selfreport measures of IEQ are the Building Use Survey (BUS) and the Center for the Built Environment (CBE) survey (Heinzerling, Schiavon, Webster \& Arens, 2013). Research using both of these measures has documented considerable dissatisfaction with open plan offices (Kim \& de Dear, 2013; Leaman \& Bordass, 1999). While issues of lack of visual privacy and visual distractions occur, complaints about noise level and associated distraction appear to be very common and distressing for employees (Kim \& de Dear, 2013; Lee, Lee, Jeon, Zhang \& Kang, 2016). A survey of over 40,000 occupants in 304 office buildings using the CBE measure of indoor environmental quality found that high noise levels and lack of sound privacy were 
among the most problematic issues for employees in OPOs (Kim and de Dear, 2013). For this reason, we have chosen to concentrate on the auditory environment in this research.

Research has shown that noise in OPOs can result in increased perceived cognitive workload (Smith-Jackson \& Klein, 2009), impaired concentration (Banbury \& Berry, 2005), and reduced energy and motivation (Jahncke, Hygge, Halin, Green \& Dimberg, 2011), cognitive performance (Lamb \& Kwok, 2016), and psychological and physiological well-being (Danielsson \& Bodin, 2008; Langer, Taylour \& Smith, 2020; Pejtersen, Feveile, Christensen \& Burr, 2011). Although perceived noise level and noise distraction are common complaints in surveys of employees working in open plan offices, objective levels and properties of the office acoustic environment are seldom measured or manipulated. In a recent review of the effects of office environments on employee well-being, Colenberg et al. (2020) found only four such studies and called for further research on the effects of objective acoustic properties on office occupants. We respond to this call in the current research by experimentally manipulating the acoustic environment at two levels: higher noise at a level typical of open plan offices and lower noise at a level typical of private offices. Further, we go beyond occupant opinion surveys to measure the effects of noise on objective performance and physiological stress responses in addition to self-reports.

\section{A Human Resource Role in Workspace Design}

The role of human resources in the mutual gains approach in HRM has been the subject of increasing attention by scholars in recent years as the relationships between a healthy workplace, collective well-being, and organizational performance have been more clearly documented (see Ho \& Kuvaas, 2020; Huettermann \& Bruch, 2019 for examples). As individuals return to shared work environments post-pandemic in gradual, staged, and partial ways, HR experts are well positioned to advocate in a data-driven way for mutual gains in the re-design of workspaces. The human resource function will play an increasing role in this 
new landscape to optimise well-being outcomes for employees and performance outcomes for employers. It is likely that many organizations will shift to hybrid work arrangements post-pandemic, in which employees regularly work both from home and in the office.

Companies are now considering how the purpose and layout of office spaces may change to better fit employee needs, such as connecting with colleagues and conducting collaborative work when needed, while also reducing the negative effects of the noisy and high-density open plan offices of the past (Davis, Leach \& Clegg, 2011; Elsbach \& Pratt, 2007). It is important that HR experts take an evidence-based approach to the recommendations they make in regard to workspace design.

We contribute to this evidence base by providing a rigorous approach to determining the true effects of workspace noise on a wide range of outcomes relevant to employee performance and well-being. As mentioned, most existing research on OPO effects uses survey designs in which employee perceptions of noise are correlated with their self-reports of outcomes such as satisfaction, performance, and health, usually while working in a single type of workspace. Attributing causality to the workspace is difficult, much less identifying which aspect of the workspace is actually problematic and should be a target for remediation. While this kind of survey work raises interesting issues and should be considered by HR experts, it will be most useful and convincing if paired with experimental demonstrations that objectively manipulated office design features cause objectively measured employee outcomes.

This paper uses a repeated measures experimental design in which the same individuals work under two noise conditions which are carefully manipulated to simulate typical open plan and private office noise levels, bearing the advantage of reducing variability and increasing statistical power (Verma, 2015). This allows causal conclusions to be reached about the effects of the objective auditory environment and well-being indicators 
(Christiansen et al., 2014). In addition, we collect both objective and subjective measures of a range of relevant outcomes which research suggests may be affected by noise exposure. These include a total of nine indicators covering cognitive performance, a number of physiological measures of the stress response, and both subjective and objective measures of affective responses. Some of these measures require special instrumentation and cannot be collected in field settings. Our use of a comprehensive multimodal approach for assessing responses to noise allows for a nuanced understanding of how environmental stressors may affect some types of outcomes but not others. Taken together, existing field surveys of employee perceptions of Indoor Environmental Quality plus laboratory-based research demonstrating causal effects of specific auditory environments on objectively measured outcomes will best support the decisions and recommendations of HR experts considering workspace design post-COVID.

\section{Office Noise and Employee Responses}

Offices are never entirely silent. In enclosed private offices, steady background noise comes from ventilation and computer fans, with intermittent noise from the keyboard, phone, and computer of the occupant, plus the possibility of passing footsteps or conversations outside the office door. On average, the background noise in a private enclosed office is about 39db(A) (Kaarlela-Tuomaala, 2009). In open plan offices, noise sources from computers are magnified by the number of people present, by shared facilities such as copy machines and elevators, by footsteps, paper shuffling, drawer opening and closing by other occupants, and by phone and face to face conversations held by others in the room (Haapakangas et al., 2014; Haka, 2009; Kostellari et al., 2010; Senan et al., 2018). These noises may be exacerbated by high occupant density and the typically "hard" acoustical properties of OPOs. On average, the background noise in an OPO is on average between 52 and 58db(A) (Delle Macchie, 2018; Hoogendoorn, 1973). Below, we develop rationales for 
the effects of noise on three categories of outcomes: cognitive performance, physiological stress responses, and affect.

Cognitive Performance. Attention and working memory theory (Baddeley \& Hitch, 1974) from cognitive psychology provides a potential explanation for why noise may reduce cognitive performance. The working memory model describes the attentional and short-term memory components that underpin performance in a wide range of cognitive tasks. The original Baddeley \& Hitch model proposes a three-component system, which includes an attentional module (the central executive) and two short-term memory modules, one for verbal input and the other for visual input. The central executive controls the allocation of limited attentional resources to tasks, stimuli, and the two types of short-term memory. The capacity of all these components is finite.

Given the limited capacity of the memory stores, irrelevant information is predicted to interfere with the perception and processing of task relevant information in the same domain. Specifically, it has been shown that noise in form of irrelevant speech will load the short term auditory/verbal memory store so that less capacity is available for processing task relevant verbal information (Colle \& Welsh, 1976; Salame \& Baddeley, 1982). Moreover, abrupt taskirrelevant distractors have the capacity to capture central executive functions, which can further reduce task performance. It therefore seems likely that open plan office noise impairs performance in two ways. Firstly, irrelevant intelligible speech may reduce processing capacity for any task that requires processing of written or spoken verbal information (such as text editing) by competing for the limited store of verbal memory. Secondly, abrupt office sounds, such as ringing phones, will capture central processing resources away from the task, which should lead to lapses in performance in all task that require focused attention.

Irrelevant speech (such as co-worker chatter or overheard phone calls) has been shown to be the most disturbing form of noise in open plan offices because distractions arise 
not just from the level of noise but also the meaning of the conversation which can hijack attention (Beaman, 2005; Venetjoki et al., 2006), Yadav \& Cabrera, 2019) and reduce cognitive performance (Di Blasio et al., 2019). For instance, productivity has been found to decrease by up to two-thirds when employees are exposed to conversations by colleagues (Iannace et al., 2018; Węziak-Białowolska et al., 2018). In the laboratory, Haapakanagas and colleagues (2014) showed that speech noise negatively affects performance on tasks involving both short and long-term memory. In the presence of speech distractors, individuals are more likely to re-read previously read words or have higher fixation on single words during a reading task (Chauchard et al., 2011; Yan et al., 2018), thereby interfering with their ability to extract and understand the meaning of the text. Furthermore, Liebl and colleagues (2016) have shown that variable and unpredictable sounds such as speech are particularly detrimental to performance since they are more difficult to habituate to. These studies suggest the likelihood that deficits in attention and working memory are the reasons that noise negatively influences cognitive performance.

Hypothesis 1: Cognitive performance will be lower in the open plan office noise condition than the private office noise condition.

Physiological Stress Responses. In general, individuals feel stressed when demands exceed the resources they have to cope, in such a way that their well-being or goals are threatened (Lazarus \& Folkman, 1984). Noise creates additional cognitive demands and requires the application of resources and compensatory effort to maintain attention to one's central task (Szalma \& Hancock, 2011). Coping with the demands of noise should increase arousal in the short term and deplete an employee's store of job resources over the longer term, leaving less available to sustain performance and threatening feelings of self-efficacy. Social psychology work on ego depletion (Baumeister, Muraven \& Tice, 2000; Baumeister, Vohs, \& Tice, 2007) also suggests that having to exert self-control to maintain focus on a task depletes 
self-control resources, leading to poorer performance and self-control failures on subsequent tasks unless resources are replenished (e.g., by rest).

Over the longer term, noise exposure is associated with increased sickness and absence in employees (Chou, Lu, \& Huang, 2016; Clausen, Kristiansen, Hansen, Pejtersen, \& Burr, 2013; Kristiansen, 2010). We suggest that work environments that feature high levels of noise will also have near-term effects on physiological stress responses. Doggett and colleagues (2021) found that task conditions imposing higher verbal working memory load (as noise does) led to significant increases in physiological arousal, as indicated across multiple measures such as heart rate, heart rate variability, and electrodermal activity. In general, noise increases arousal in humans, for example, changes in skin resistance, heart rate, heart rate variability, blood pressure, metabolic rate, and muscle tension (Szalma \& Hancock, 2011). Studies have shown that exposure to workplace noise results in physiological consequences such as elevated cortisol (Kristiansen et al., 2009) and changes in heart rate variability (HRV) and blood pressure (Chang, Jain, Wang, \& Chan, 2003; Kristiansen et al., 2009).

Hypothesis 2: Physiological stress will be greater in the open plan office noise condition than the private office noise condition.

Affective Responses. Well-being at work is often considered to contain both physical and psychological components. Above, we suggested that noise would increase physiological indicators of stress. Here we suggest that noise will also result in greater negative mood and emotion. Noise distractions that threaten goal progress are likely to create negative emotions such as frustration (Lazarus, 1991). Noise has been shown to have a detrimental effect on mood both directly as a response to the noise and the need to exert additional effort (Acun \& Yilmazer, 2018) and indirectly due to frustration associated with reduced performance (Zohar, Tzischinski \& Epstein, 2003; see Puranik, Koopman, \& Vough, 2020 for a review). 
Studies on the aftereffects of exposure to noise have shown that coping with unpredictable noise results in reduced frustration tolerance (see Cohen, 1980 for a review). Lamb and colleagues (2016) utilised surveys over an 8 month period to assess the effects of IEQ on perceptions of well-being in office settings, finding that noise annoyance was associated with negative mood. Virtually all previous research on noise and affective outcomes has relied upon self-reports of affect. We pioneer the use of an objective means of coding affective states via facial expression recognition technology in addition to self-reported mood. Hypothesis 3: Affective reactions will be more negative in the open plan office noise condition than the private office noise condition.

\section{Method}

\section{Design, Procedure, and Treatment}

Participants completed a cognitive performance (proof-reading) task under two conditions: simulated open plan office background high noise vs. simulated private office low noise. The order of the two conditions was counter-balanced across participants, to avoid bias due to fatigue and training effects. Participants were tested individually in the same room. In the high noise condition, a combination of typical open-plan office sounds was played to the participants while they were engaged in the proof-reading task. The soundscape included people speaking, walking, printing papers, ringing telephones, and keyboard typing noises. The sound was presented via a Bluetooth JBL Flip 3 portable speaker that was mounted vertically on a stand above head height, that was placed in the middle of the room approximately $210 \mathrm{~cm}$ away from the participant) to create a non-directional sound effect. The average sound pressure level was $59.1 \mathrm{~dB}$ (A) (measured at the participants' head location, via a Casella CEL-63X sound pressure meter and expressed as an equivalent sound level). The choice of this sound level was based on literature demonstrating that typical values for background noise in open plan offices range from 52 to $58 \mathrm{~dB}(\mathrm{~A})$ (Delle Macchie, Secchi \& Cellai, 2018). In the low 
noise condition, the room was much quieter during performance of the proof-reading task, with an average sound pressure level of $36.3 \mathrm{~dB}(\mathrm{~A})$ (resulting from air-conditioning and computer fan noise).

To obtain physiological measures of stress, a SHIMMER TM 3 GSR + optical pulse oximeter was placed on the participants' right ear lobe to measure heart rate and two GSR electrodes were placed over the arch of the participant's right foot to measure skin conductivity. The foot was chosen as recording location, since the participants needed to move their hands for the proof-reading task. Each participant underwent both task conditions (high noise vs. low background noise), each lasting 10 minutes in a counter-balanced order. The short task duration was chosen to avoid pronounced fatigue effects, given the within-subject design. Eight minutes were allocated to the proofreading task, and the remaining 2 minutes were allocated for the completion of the self-report measure of positive and negative affect.

\section{Participants}

G* Power (version 3.1.9.4) analysis was conducted beforehand to calculate the minimum sample size required to ensure adequate power and reflect the probability of detecting significant differences. Estimations were conducted using t-tests for differences between two dependent means (matched-pairs) with medium effect sizes of $d=0.5$, and a statistical power of .80 . The results of the calculation indicated that a minimum sample size of 34 participants was required. To cater for potential data loss, 43 participants were recruited. Forty healthy subjects with an age range of $17-44$ years and a mean age of 22.65 years $(\mathrm{SD}=6.15)$ participated in this study. Participants consisted of 34 female and 6 male undergraduates and post-graduate students recruited predominantly from a psychology subject pool. Those who were undergraduate students participated in exchange for course credit points, no other incentives were provided. The minimum age for participants to take part in the study was 17 years old. The maximum age of 45 years old was implemented to avoid any cognitive decline related 
outlier effects (Peich et al., 2013). Due to the nature of the proof-reading task, participants were required to have university-level English and normal vision and hearing (corrected if necessary). Due to technical faults (i.e. poor signal quality), there are only 38 data sets for the two heartrate measures.

\section{Measures}

\section{Cognitive Performance}

To measure cognitive performance in an ecologically valid way, a proof-reading task was employed, as such a task is similar to many clerical tasks performed by knowledge workers in offices. For this, two different text excerpts (4200 words each) from On the Origins of Species (Darwin, 1873) were used. The text was chosen since it is copyright free, is unlikely to evoke emotions, and does not contain many uncommon terms. Participants were instructed to highlight typographical errors in the text using the computer mouse (spell-check was disabled). In total, 80 typographical errors were introduced in each text, on average one error for every three lines of text. This large number of errors was chosen to avoid a ceiling effect, (i.e. at $100 \%$ performance level it would be impossible to detect differences between conditions). The typographical errors always involved changing the position of two non-initial letters. An example of an errors is: "recieved" instead of "received." The rationale behind this is that research has shown that that alterations in the middle of the word are harder to notice (Schoonbaert, \& Grainger, 2004; Perea et al., 2012). The performance measure was the number of correctly identified errors.

\section{Objective Physiological Measures of Stress}

It is well established that physiological measures of heart rate, heart rate variability, and electro-dermal activity are reliable physiological indicators of stress (Everly \& Lating, 2013).

\section{Heart rate measures}


We utilized two separate measures of heart rate. Firstly, we captured the heart rate of the participants, which is simply the number of beats of the heart per minute. The positive correlation between heart rate, as a measure of physiological arousal, and stress is well established; the higher the heart rate, the greater the impact of the stressor on the individual (e.g. Vrijkotte et al. 2000). We also measured heart rate variability (HRV), which is the change in the time intervals between adjoining heart beats. Psychological stress is indicated by lower levels of HRV, i.e. less variation between heartbeats (Kim et al. 2018). There are several ways to compute HRV. One of the most common measures is Root Mean Square of the Successive Differences (RMSSD; measured in milliseconds), which is a reliable indicator of short-term, time-interval HRV (Stapelberg et al., 2018). For two participants heart rate measure could not be reliably obtained, for this reason analysis of heart rate and heart rate variability is conducted on 38 participants.

Electrodermal activity. Electro-dermal activity (EDA), measured in microsiemens $(\mu \mathrm{S})$, quantifies electrical skin conductance from the sweat glands in the palms of the hand, soles of feet or fingertips. Electro-dermal activity is an autonomic and involuntary bodily response whereby the individual sweats more in stressful situations, although this increased sweating may be imperceptible to the human eye (typical skin conductance levels are within the range of 1-20 $\mu \mathrm{S})$. The two components of EDA are the skin conductance level, a slow changing (tonic) time interval measure of skin conductance, and skin conductance response, which captures abrupt (phasic) increases or peaks. The skin conductance level was measured by averaging the low pass filtered (at $6 \mathrm{~Hz}$ to remove phasic signals) signal. Skin conductance response was measured in form of GSR peaks per minute. Both measures are widely used indicators of physiological stress, with higher levels being indicative of increased stress (Birenboim, et al., 2019; Reeves et al., 2019; Zhai, \& Barreto, 2006; Zhang, Lian, \& Wu, 2017).

\section{Measures of Affect}


Affect (mood and emotions) was measured both by self-report and objectively.

\section{Self-reported Positive and Negative Affect}

In each of the two conditions, participants reported their mood immediately after the proofreading task using the Positive and Negative Affect Schedule (PANAS) (Watson et al., 1988). The PANAS is a widely used and psychometrically sound scale for measuring activating positive and negative affect (Muaremi et al., 2013; Pabst et al., 2013). High positive affect (PA) reflects the experience of happiness, enthusiasm, and alertness. High negative affect (NA) refers to experiences of stress and displeasure, such that high NA is indicated by states such as nervousness, hostility, and distress (Watson et al., 1988). The temporal instructions of the scales can range from the "present moment" to "during the past year." As the nature of the study focuses on the participants' current affect, the instructions of "present moment" were used. Positive and negative affect are each assessed with ratings of 10 affect terms on a 5 point scale.

\section{Facial Expression of Emotion}

Automated facial expression analysis is a relatively novel instrument in research, however it has promise as a means of objectively assessing emotions in research settings (Das et al., 2013; Jack et al., 2016). The first empirically validated approach to classifying emotions based on facial expressions was called the facial action coding system (Ekman, 1988; Lerner et al., 2007). The emotions recognized by the facial action coding system were based on the six universal facial expressions (Ekman, 1988). In the current study, facial expressions were recorded by a high-definition webcam and analysed using iMotions (Version 8.1.1) AFFECTIVA (Kulke et al., 2020; McDuff et al., 2013). The program includes a real time analysis of facial features (such as eyebrow furrow and upper lip movements), and an analysis based on the basic emotions of anger, fear, disgust, sadness, and joy (Ekman, 1988; Mayo et al., 2019). The software employs an algorithm which has analysed over seven million faces 
(Farnsworth, 2019), and has been used in previous stress research (Harley, 2016; Mayo et al., 2019). The detection threshold for emotions used by AFFECTIVA was set to $25 \%$, since previous studies have suggested optimal thresholds ranging from $20 \%$ to $50 \%$ for (Calvo et al., 2016; Goren \& Wilson, 2006). To limit the number of multiple statistical comparisons, only anger and disgust were selected for analysis in the current study. Anger was chosen since prior literature has linked noise distractors with increased feelings of annoyance (Guski, FelscherSuhr \& Schuemer, 1999). Disgust was chosen, since norm-violating behaviour by others (in the current study the generation of unwanted noise) can elicit so-called socio-moral disgust, (Benoît Dubreuil, 2010) which shares facial characteristics with core disgust (which is elicited by gustatory distaste or the observation of contaminants (Vicario, 2017)). There was no reason to expect that noise would affect fear, joy, or the low-arousal negative emotion of sadness.

\section{Results}

Data were analysed by paired-sample t-tests on each dependent variable with a MANOVA for the potentially correlated physiological indicators. The current study has nine dependent measures in total: cognitive performance (errors detected on the proof-reading task), skin conductance response, skin conductance level, heart rate, heart rate variability (RMSSD), facial emotions (anger and disgust), self-reported affect (positive and negative mood).

\section{Cognitive Performance}

We used a paired t-test to compare the two conditions (high noise vs low noise) for differences in cognitive performance levels as measured by the proofreading task. There was no statistically significant difference $(\mathrm{t}(39)=1.09, \mathrm{p}=.283)$ in the average number of errors detected in the experimental condition $(\mathrm{M}=11.00, \mathrm{STD}=4.99)$ compared to the control condition $(\mathrm{M}=10.33, \mathrm{STD}=4.73)$.

\section{Objective Physiological Measures of Stress}


To assess the overall impact of noise on electrophysiological indicators of stress, we conducted a MANOVA comparing the two conditions across all four dependent measures. The analysis was statistically significant $(\mathrm{F}(4,34)=4.660, \mathrm{p}=.004)$. However, subsequent univariate tests showed that only phasic skin conductance response and heart rate were significantly different. Below we individually review the outcomes of each of the four physiological measures.

\section{Electrodermal activity}

We assessed the data for difference in tonic and phasic skin conductance across the two conditions. Phasic skin conductance response was significantly higher $(\mathrm{t}(39)=2.08, \mathrm{p}=0.044)$ in the open plan office noise condition $(\mathrm{M}=3.06, \mathrm{STD}=2.69)$ than in the low noise condition $(\mathrm{M}=2.47, \mathrm{STD}=2.47)$. For tonic skin conductance level, there was no significance effect of the noise condition $(\mathrm{t}(30)=1.78, \mathrm{p}=.083)$, though the mean trended higher in the high noise condition $(\mathrm{M}=11.91, \mathrm{STD}=10.65)$ than the low noise condition $(\mathrm{M}=10.52, \mathrm{STD}=10.54)$.

\section{Heart rate measures}

Comparing the two conditions for differences in heart rate, we found that heart rate was higher in the high noise condition $(\mathrm{t}(37)=2.61, \mathrm{p}=.013)(\mathrm{M}=76.83, \mathrm{STD}=13.46)$ than in the low noise condition $(\mathrm{M}=75.49, \mathrm{STD}=12.69)$. For heart rate variability $(\mathrm{RMSSD})$ we did not find a significant effect $(\mathrm{t}(37)=0.188, \mathrm{p}=.852)$ (high noise $\mathrm{M}=50.36, \mathrm{STD}=30.03$; low noise $\mathrm{M}=51.00$, $\mathrm{STD}=33.00$.

\section{Measures of Affect}

\section{Self-reported Positive and Negative Affect}

We used two paired t-tests to compare the noise conditions for differences in positive and negative affect. Positive affect was significantly lower in the high noise condition $(\mathrm{t}(39)=3.26$, $\mathrm{p}=0.002)(\mathrm{M}=17.3 ; \mathrm{STD}=6.27)$ relative to the low noise condition $(\mathrm{M}=20.3, \mathrm{STD}=6.82)$. 
Negative affect was significantly higher $(\mathrm{t}(39)=3.59, \mathrm{p}=0.001)$ in the high noise condition $(\mathrm{M}=16.05 ; \mathrm{STD}=4.87)$ relative to the low noise condition $(\mathrm{M}=12.85, \mathrm{STD}=3.59)$.

\section{Facial Expression of Emotion}

We used two paired t-tests to compare the two conditions for differences in the percent of time in which the facial expression of anger and disgust were present. We detected significantly $(\mathrm{t}(39)=2.24, \mathrm{p}=0.031)$ more disgust expressions in the high noise $(\mathrm{M}=0.17 \%$, $\mathrm{STD}=0.27)$ than in the low noise condition $(\mathrm{M}=0.08 \%, \mathrm{STD}=0.16)$. It should be noted that,

given the 8-minute duration of the proof-reading task, this translates to an average duration of disgust expression of $\sim 1$ second in the high noise condition, which is not present in the silent condition. So, despite the statistical significance the effect is very subtle. Conducting the same contrast for facial expression of anger, we detected no significant effect $(\mathrm{t}(39)=0.989$, $\mathrm{p}=0.329)$.

In summary, five out of nine dependent variables indicated greater stress/lower mood in the open plan office noise condition than in the private office noise condition, and another other measure trended in the expected direction. The strongest effects were for self-reported mood.

\section{Discussion}

The coronavirus pandemic has brought the work environment into sharp focus, and it is critical that organizations are sensitive to the ways in which the physical work environment may impact employee well-being and performance. Although most unwelcome in itself, COVID has presented opportunities to rethink what may have been less than healthy workplaces. While noise is the most commonly cited complaint from employees working in open plan office environments, the review by Colenberg et al. (2020) highlighted a significant gap in previous research on noise in office environments. Only four studies included specific parameters of noise (Colenberg et al. (2020). In addition, most studies investigating the effects 
of workplace of noise focus just on self-reports of noise annoyance and/or performance measures (e.g., Hodzic et al., 2020; Lee \& Aletta, 2019; Haapakangas et al., 2014; Acun \& Yilmazer, 2019). While there are prior studies that reported physiological impacts of noise (Wellens \& Smith, 2006; Lee et al., 2020), they are still limited in the range of measures employed. By using simulated office environment with objectively manipulated noise levels and a wide range of objective and subjective dependent variables, our study addresses a gap in the literature. The comparison of multiple outputs measures provides not only a high level of internal validity, but it also provides important methodological insights into the relative efficiency of these measures to capture the impacts of noise.

Our results demonstrated that exposure to open plan office noise significantly affected a number of the physiological and psychological variables as expected. Hypothesis 1, that cognitive performance would be compromised by open plan office noise, was not supported. Hypothesis 2, that physiological measures would show that participants experienced greater stress under open plan office noise than quiet working conditions was supported by significant effects for two measures, and trends in the hypothesized direction on the other two. Hypothesis 3 , that affect would be more negative under open plan office noise, was supported by both selfreport mood measures and one of the two facial recognition measures of emotion.

These results are fairly convincing given that the work period in the study was only 8 minutes in each condition. In actual work settings, workers in open plan offices are exposed to noise continuously during the day (Flamme et al., 2012) and we would expect that effects on stress and affect would be greater. The short duration may also explain the non-significant results for cognitive performance. Participants may have exerted compensatory effort to sustain their performance over the short term. Given the significant results on both self-reported mood and stress, it is likely that the increased cognitive load of maintaining focus under distraction would deplete resources and damage performance following longer exposure. 


\section{Theoretical Contribution}

Our empirical work offers four main contributions to research on the physical work environment. Firstly, we demonstrate a significant causal relationship between exposure to noise typical in open plan offices vs private offices and physiological stress using objective measures in experimentally controlled conditions. Although open plan offices rarely present an immediate physical danger in terms of sound levels that could damage hearing, and the short-term physiological effects are subtle, these effects may intensify with unrelenting exposure to noise from the start to the end of the workday. Chronically elevated levels of physiological stress are known to be detrimental to mental and physical health (for an overview see Ganster \& Rosen, 2013). Exposure to noise may also act additively or interactively with other environmental stressors common in the modern open plan office, such as visual distraction as other employees move about, and interruptions from nearby colleagues or technology (Brennan et al., 2002).

Secondly, we demonstrate that open plan office noise results in less positive mood and greater negative mood compared to a quiet environment. To our knowledge, prior research has not investigated the effects of open plan office noise on mood in an experimental setting (Colenberg et al., 2020). The self-report measure of mood was responsive to even a short exposure to noise while working.

Third, we explored the use of facial recognition measures of emotion, and captured modest noise effects on disgust, potentially caused by the office noise being perceived as normviolating behaviour by others (Benoît Dubreui, 2010; Vicario, 2017). It is possible that participants supressed facial displays in the brief experiment while concentrating on their task, but we might expect displays of negative emotions to emerge as self-control resources are depleted following longer exposure to noise and the increase in compensatory effort required. More extensive use of facial recognition of emotions will add to and/or support the credibility 
of self-report measures as indicators of the well-being effects of physical work environment conditions. We recommend the use of a range of objective measures of performance and stress and well as emotion to supplement the self-report measures habitually used in management research.

Fourth, and most importantly, our study has highlighted the importance of using a multimodal approach in assessing the psychological impact of workplace stressors. The sole reliance on a task performance measure would have suggested that the office noise had no detrimental effect, whereas the affective self-report and physiological measures provided clear evidence for increased stress in the noise condition. Further, the objective physiological effects of noise complement the self-report mood effects and help to demonstrate that employees are not merely complaining but actually being affected by the auditory environment.

\section{Effects of Noise on Workplace Performance and Mood}

Moving beyond our empirical findings, we suggest a potential mechanism by which noise affects employee behavior. While the effects of noise on physiological stress are fairly immediate and more clearly established (Ising \& Kruppa, 2004), the relationship between workplace noise and affect has been largely ignored by scholars. Open plan office noise and other forms of workplace distractions or interruptions may constitute real-time affective events (Weiss \& Cropanzano, 1996). Negative mood may lead to short-term "affect driven behaviors" such as counter-productive work behavior or incivility while the affect is being experienced, especially when self-control resources have been depleted by prolonged exposure to distraction (Baumeister, 2003; Herman et al., 2018). Cumulatively over time, the frequent experience of negative affect (and lowered positive affect) would be expected to influence attitudes such as job satisfaction and organizational commitment, and subsequently “judgement driven behaviors" such as employee turnover (Ekhsan, 2019). Further research will be needed to assess the effect of work environments over longer spans of time on more 
distal measures such as these. Finally, it may be the case that noise predicts performance indirectly through mood, however we did not test that here as our rationale for performance effects was cognitive (limited attention, distraction), not affective.

\section{Practical Implications}

As organizations scramble to adapt to the wide-ranging changes to the location of work as a result of COVID-19, they have the opportunity to reconsider the design of workspaces. The human resource function in organizations will play an important role in this new landscape to optimize outcomes for both employers and employees. It seems likely that greater work from home and less time in large, crowded offices will be features of the future for some time (Baumann \& Sander, 2021). There is the opportunity to rethink the different functions of the office within this context to enhance the quality of the physical work environment to benefit human well-being and desired organizational outcomes.

The role of human resource practices in stimulating mutual gains in HRM has been the subject of increasing attention by scholars in recent years as the relationships between a healthy workplace, collective well-being, and organizational performance have become more clearly understood (see Ho \& Kuvaas, 2020; Huettermann \& Bruch, 2020 for examples). However, existing empirical studies in HRM and mutual gains provide ambiguous evidence and call for further research to investigate how (i.e., through what mechanisms) and when (i.e., depending on what contingencies) HR management may positively relate to employee well-being (van de Voorde et al., 2012) and favourable organizational outcomes. Our study adds to the understanding of the ways in which the physical work environment affects employee well-being and suggests that HR practices around the physical work environment may help produce mutual gains. While this paper focused on the effects of noise on individuals, more substantial interventions in the design of human-friendly physical 
workspaces would also require effective employee consultation, communication, and change management (Sander, Caza \& Jordan, 2019).

Research investigating the effects of open plan office environments on employee physiological and affective reactions is essential to better understand the conditions under which negative outcomes arise. Although our research suggests that both physiological stress and affect are negatively affected by noise, it is neither practical nor realistic to imagine a scenario in which organizations abandon all open plan offices. However, this study highlights the importance of understanding employee needs and preferences as well as task requirements in designing such workspaces. Organizations may wish to reconsider the extent to which open plan settings are deployed, as well as the use of acoustic treatments, sound masking technologies, reduced density and increased use of walls or partitions (Lee et al., 2020). Social interventions to limit extraneous noise, interruptions, and technological distractions may also be helpful.

If some or many employees continue work from home some of the time, it may be possible to reduce density in existing OPOs, thus reducing both visual and auditory distraction. We are all now used to instructions to socially distance and seeing COVID barriers between service providers and clients. This suggests that reducing density and raising the height of walls between co-worker cubicles might be wise to reduce transmission of airborne illnesses, with the additional benefit of providing more employee privacy and less visual distraction. If supported by sufficient research, the joint effects of risk of infection in dense OPOs together with increasing understanding of the psychological effects of noise and other distractions may tip the balance back toward private or semi-private offices for more employees.

The HRM mutual gains perspective can assist organisations to optimise their work environments by better understanding the requirements and challenges of the physical work 
environment for employees. While alterations to address noise in OPOs such as the installation of acoustic treatments such as wall and ceiling panels, increased partitions and sound masking, can be costly, the imperative for doing so is significant. Improvements to IEQ have been estimated to increase productivity by $5 \%$ (Fisk \& Rosenfeld, 1997), and the direct cost of poor IEQ to productivity, exclusive of illness, has been estimated at between $\$ 20$ and $\$ 160$ billion dollars annually in the US alone (Fisk, 2000). As part of a larger concern with occupational health, HR specialists should monitor physical and psychological stressors linked to the physical work environment. HR practitioners can contribute to mutual gains for employees and employers in several ways. Firstly, they can catalyse modifications to the physical work environment through such measures as acoustic treatment, work area redesign, or social interventions to better suit individual and team needs and task requirements. As our study has highlighted a causal effect of noise on physiological stress and affect, objective assessment of post-occupancy noise levels is an important step in identifying levels of risk of noise annoyance to employees. Installation of additional partitions, as well as acoustic wall and ceiling treatments may be necessary to reduce the effects of noise in OPOs for employees. Secondly, as both employees and the work they undertake change continuously, awareness of the effects of the physical work environment on employee well-being and performance allows HRM to manage the implementation and utilization of flexible work arrangements in a more responsive manner. For example, if employees have the choice to work in different locations such as their home, the effects of noise may be reduced as a result of reduced exposure during the working week. By understanding the impact that background noise in offices has on stress and mood, HR practitioners are better placed to design and modify workplaces to minimise these effects and support both employee well-being and organizational performance.

\section{Limitations and Future Direction}


Open plan office environments are a complex stimulus. In addition to noise levels, they vary in features such as density, temperature and air flow, presence or absence of partitions between workstations, greenery, soft furnishings, natural light, and extent of movement by other occupants (Davis, Leach \& Clegg, 2011; Elsbach \& Pratt, 2007; Kim \& de Dear, 2013). Some features provide additional layers of distractions or stressors for occupants while others help to remediate distractions. However, exploring a large number of features and their interactions in a single study with experimental methods and objective measures is near impossible. Instead, we focused on the lack of thorough understanding of the effects of noise alone, after which further research can explore the layering of other harmful or supportive features in open plan offices. In terms of interventions, it is likely that some efforts to reduce noise (e.g. by reducing density and adding partitions) would also reduce other common problems such as visual and social distractions.

Although our study found significant negative effects of noise on both mood and stress, there are limitations that could be addressed in future research. Firstly, the most significant limitation is the short period of noise exposure. This may account for the non-significant results on the cognitive performance task. It seems likely that performance would be more likely to decline under prolonged noise exposure. Continuing to focus on a task under distraction requires compensatory effort, indicated here by physiological changes, and eventually may deplete self-control resources (Baumeister, Vohs, \& Tice, 2007). The modest results for facial emotion recognition probably also suffered from the short duration of the work periods. Perhaps when used over a longer period of time, clearer and more sensitive aggregates of emotional expressions can be developed. A second limitation is the use of a single task and cognitive performance measure, while distraction effects may differ depending on the demands of the task, e.g. extent to which working memory is required or familiarity with the task (new versus well-learned activity). Our study could be replicated in 
different age groups as working memory performance and capability for switching attentional focus reduces as age increases (Verhaeghen \& Basak, 2005).

Additional research is needed on the effects of the physical work environment on different types of work tasks. For example, very simple jobs may benefit from some environmental stimulation to counter boredom and mind-wandering (Fisher, 1993), whereas those requiring concentration may be increasingly compromised as environmental distractions increase. The effects of interruptions can be neutral or even positive dependent on a number of factors including whether the interruption was welcome, timely, or relevant to an existing task (Feldman \& Greenway, 2020). Our findings could be extended by undertaking longer laboratory studies using tasks with differing levels and types of cognitive demands. We used a cognitive performance task requiring careful attention to detail, but it would be interesting to see how noise and other office distractions influence different tasks such as those requiring creativity. One study found that a moderate level of ambient noise enhanced performance on creative tasks compared to a low level ambient noise (Mehta, Zhu \& Cheema, 2012). Future research could also investigate whether the effects of noise on some dependent variables is mediated by other factors treated as dependent variables in our study, for instance, whether mood is a by-product or a cause of physiological changes.

Individual differences may also condition the extent to which environmental distractors are harmful to well-being and performance. For example, research has shown that individuals vary in their sensitivity to noise (Lee \& Griffin, 2013) and reactions to open plan offices (Maher \& Von Hippel, 2005; Sander, Caza \& Jordan, 2019). In addition, personality has been demonstrated to have differential impact on self-rated distraction, job satisfaction and job performance in different office types (Seddigh, Bernstrom, Platts \& Westerlund, 2016).

We simulated the acoustical environment of an open plan office in the lab. Further laboratory investigations of simulated office environments could be useful in a number of 
ways. First, as demonstrated here, standard measures of performance, sophisticated physiological measures of stress, and objective measures of emotional experience are possible in the lab but probably not in real offices. The laboratory also offers the opportunity to isolate and explore specific aspects of physical work environment distractions. In the case of noise, further research might manipulate noise volume, variability, speech intelligibility, and number of speakers as well as simulate the application of alternative acoustical treatments. This would be a low-cost way to gather information which can be used in designing workplace environments to support both performance and employee well-being.

Further, laboratory research can be used to investigate the additive and interactive effects of different kinds of workplace demands in the form of auditory distraction in combination with types and frequency of visual distraction (e.g., people moving about), and interruptions by humans and/or technology. Different forms of distraction may all deplete the same limited store of resources and collectively account for the negative effects seen in many open plan offices. Mitigation strategies can also be tested in the lab prior to installation in actual offices. For instance, low or no walls between workstations are a feature of many open plan offices. Higher partitions should reduce visual distractions and may also reduce acoustical distraction. The effects of social interventions such as e-mail free hours and quiet times could also be explored.

Outside of laboratory settings, HR managers may wish to engage in field experiments with density and/or partition height as employees return to work following COVID restrictions. Dependent variables would likely be limited to self-report $\mathrm{mood} /$ fatigue/satisfaction measures, though it may be possible to capture some performance measures as well depending on the workplace (e.g. claims processed per day captured electronically). This field work would allow for longer exposure periods to be tested and be a 
good complement to laboratory research with physiological measures and in which more levels/intensities of various physical environment attributes are independently manipulated.

Acknowledgements: The authors wish to thank Cynthia D. Fisher for her contribution in the development of this manuscript. 


\section{References}

Acun, V., \& Yilmazer, S. (2018). A grounded theory approach to investigate the perceived soundscape of open-plan offices. Applied Acoustics, 131, 28-37.

Ayoko, O. B., \& Ashkanasy, N. M. (2020). The physical environment of office work: Future open plan offices. Australian Journal of Management, 45(3), 488-506.

Baddeley, A. D., \& Hitch, G. (1974). Working memory. Psychology of Learning and Motivation, 8, 47-89.

Banbury, Simon P., and Dianne C. Berry. "Office noise and employee concentration: Identifying causes of disruption and potential improvements." Ergonomics 48, no. 1 (2005): 25-37.

Baumann, O. \& Sander, E. (2021). Psychological Impacts of Remote Working under Social Distancing Restrictions. In: Handbook of research on remote work and worker wellbeing in the post-COVID-19 era. Daniel Wheatley, Irene Hardill \& Sarah Buglass. IGI Global. https://doi.org/10.4018/978-1-7998-6754-8.ch001

Baumeister R. F. (2003). Ego depletion and self-regulation failure: a resource model of selfcontrol. Alcoholism, clinical and experimental research, 27(2), 281-284. https://doi.org/10.1097/01.ALC.0000060879.61384.A4 
Baumeister, R. F., Muraven, M., \& Tice, D. M. (2000). Ego depletion: A resource model of volition, self-regulation, and controlled processing. Social cognition, 18(2), 130-150.

Baumeister, R. F., Vohs, K. D., \& Tice, D. M. (2007). The strength model of selfcontrol. Current directions in psychological science, 16(6), 351-355.

Beaman, C. P. (2005). Auditory distraction from low-intensity noise: a review of the consequences for learning and workplace environments. Applied Cognitive Psychology, 19(8), 1041-1064.

Birenboim, A., Dijst, M., Scheepers, F., Poelman, M., \& Helbich, M. (2019). Wearables and location tracking technologies for mental-state sensing in outdoor environments. The Professional Geographer, 71(3), 1-13.

Brennan, A., Jasdeep, S. C, \& Kline, T. (2002). Traditional versus open office design: A longitudinal field study. Environment and Behavior, 34, 279-299.

Calvo, M. G., Avero, P., Fernández-Martín, A., \& Recio, G. (2016). Recognition thresholds for static and dynamic emotional faces. Emotion, 16(8), 1186-1200.

Chang, T. Y., Jain, R. M., Wang, C. S., \& Chan, C. C. (2003). Effects of occupational noise exposure on blood pressure. Journal of Occupational and Environmental Medicine, 45(12), 1289-1296. 
Chou, C., Lu, C., \& Huang, R. (2016). Effects of different ambient environments on human responses and work performance. Journal of Ambient Intelligence and Humanized Computing, 7(6), 865-874.

Christensen, L. B., Johnson, R. B., Turner, L. A., \& Pearson. (2014). Research methods, design, and analysis (14th ed.). Pearson.

Clausen, T., Kristiansen, J., Hansen, J. V., Pejtersen, J. H., \& Burr, H. (2013). Exposure to disturbing noise and risk of long-term sickness absence among office workers: A prospective analysis of register-based outcomes. International Archives of Occupational and Environmental Health, 86(7), 729-734.

Cohen, S. (1980). Aftereffects of stress on human performance and social behavior: a review of research and theory. Psychological bulletin, 88(1), 82-108.

Colenberg, S., Jylhä, T., \& Arkesteijn, M. (2020) The relationship between interior office space and employee health and well-being - a literature review. Building Research \& Information, (ahead of print) 1-15.

Colle H. A., Welsh A. (1976). Acoustic masking in primary memory. J. Verbal Learn. Verbal Behav. 15 17-31.

Danielsson, C. B., \& Bodin, L. (2008). Office type in relation to health, well-being, and job satisfaction among employees. Environment and behavior, 40(5), 636-668. 
Darwin, C. (1859). On the Origin of Species by Means of Natural Selection, Or, The Preservation of Favoured Races in the Struggle for Life. John Murray, Albemarle Street; 1859.

Das, S., \& Yamada, K. (2013). Evaluating Instantaneous Psychological Stress from Emotional Composition of a Facial Expression. Journal of Advanced Computational Intelligence and Intelligent Informatics, 17(4), 480-492.

Davis, M. C., Leach, D. J., \& Clegg, C. W. (2011). The physical environment of the office: Contemporary and emerging issues. In G. P. Hodgkinson \& J. K. Ford (Eds.), International review of industrial and organizational psychology: Vol. 26. International review of industrial and organizational psychology 2011 (p. 193-237). Wiley Blackwell.

Delle Macchie, S., Secchi, S., \& Cellai, G. (2018). Acoustic issues in open plan offices: A typological analysis. Buildings, 8(11), 161.

Di Blasio, S., Shtrepi, L., Puglisi, G. E., \& Astolfi, A. (2019) A Cross-Sectional Survey on the Impact of Irrelevant Speech Noise on Annoyance, Mental Health and Well-being, Performance and Occupants' Behavior in Shared and Open-Plan Offices. International Journal of Environmental Research and Public Health. 16, 280. 
Doggett, R., Sander, E., Birt, J., Ottley, M., Baumann, O. (2021) Using virtual reality to evaluate the impact of room acoustics on cognitive performance and well-being. Frontiers in virtual reality. doi: 10.3389/frvir.2021.620503

Dubreuil, B. (2010). Punitive emotions and norm violations. Philosophical Explorations. 13(1), 35-50

Ekhsan, M. (2019). The influence job satisfaction and organizational commitment on employee turnover intention. Journal of Business, Management, and Accounting. 1, 4855.

Ekman, P., Friesen, W. V., \& O'Sullivan, M. (1988). Smiles when lying. Journal of Personality and Social Psychology, 54(3), 414-420.

Elsbach, K. D., \& Pratt, M. G. (2007). 4 the physical environment in organizations. Academy of Management Annals, 1(1), 181-224.

Everly, G.S., \& Lating, J.M. (2013). A Clinical Guide to the Treatment of the Human Stress Response. 3rd ed. New York, NY: Springer (2013). 485 p. doi: 10.1007/978-1-4614$5538-7$

Farnsworth, B. (2019, August 18). Facial Action Coding System (FACS) - A Visual Guidebook. imotions. https://imotions.com/blog/facial-action-coding-system/ 
Feldman, E., \& Greenway, D. (2020). It's a matter of time: The role of temporal perceptions in emotional experiences of work interruptions. Group \& Organization Management, 46(1), 70-104.

Fisher, C.D. (1993). Boredom at work: A neglected concept. Human Relations, 43, 395-417.

Fisk, W. J. (2000). Health and productivity gains from better indoor environments and their relationship with building energy efficiency. Annual review of energy and the environment, 25(1), 537-566.

Fisk, W. J., \& Rosenfeld, A. H. (1997). Estimates of improved productivity and health from better indoor environments. Indoor air, 7(3), 158-172.

Flamme, G. A., Stephenson, M. R., Deiters, K., Tatro, A., van Gessel, D., Geda, K., Wyllys, K., \& McGregor, K. (2012). Typical noise exposure in daily life. International journal of audiology, 51 Suppl 1(0 1), S3-S11.

Ganster DC., Rosen CC. (2013). Work stress and employee health: a multidisciplinary review. Journal of Management, 39,1085-122.

Goren, D., \& Wilson, H. R. (2006). Quantifying facial expression recognition across viewing conditions. Vision Research, 46(8-9), 1253-1262. 10.1016/j.visres.2005.10.028

Guski, R. (1999). Personal and social variables as co- determinants of noise annoyance. Noise \& Health 3, 45-56. 
Haapakangas, A., Hongisto, V., Hyönä, J., Kokko, J., \& Keränen, J. (2014). Effects of unattended speech on performance and subjective distraction: The role of acoustic design in open-plan offices. Applied Acoustics, 86, 1-16.

Haka, M., Haapakangas, A., Keränen, J., Hakala, J., Keskinen, E., \& Hongisto, V. (2009). Performance effects and subjective disturbance of speech in acoustically different office types - a laboratory experiment. Indoor Air, 19, 454-467.

Harley, J. M. (2016). Measuring emotions: A survey of cutting edge methodologies used in computer-based learning environment research. Emotions, Technology, Design, and Learning, 89-114. 10.1016/b978-0-12-801856-9.00005-0

Heinzerling, D., Schiavon, S., Webster, T., \& Arens, E. (2013). Indoor environmental quality assessment models: A literature review and a proposed weighting and classification scheme. Building and environment, 70, 210-222.

Herman, A. M., Critchley, H. D., \& Duka, T. (2018). The role of emotions and physiological arousal in modulating impulsive behaviour. Biological psychology, 133, 30-43. https://doi.org/10.1016/j.biopsycho.2018.01.014

Ho, H., \& Kuvaas, B. (2019). Human resource management systems, employee well-being, and firm performance from the mutual gains and critical perspectives: The well-being paradox. Human Resource Management, 59(3), 235-253.

Hodzic, S., Kubicek, B., Uhlig, L., \& Korunka, C. (2020). Activity-based flexible offices: effects on work-related outcomes in a longitudinal study. Ergonomics, 1-19. Advance online publication. $\underline{\text { https://doi.org/10.1080/00140139.2020.1850882 }}$ 
Hoogendoorn, K. (1973) How to cope with noise in open plan offices. Building Research and Practice, 1(4), 202-206.

Huettermann, H., \& Bruch, H. (2019). Mutual gains? Health-related HRM, collective wellbeing and organizational performance. Journal of Management Studies, 56(6), 10451072.

Iannace, G., Ciaburro, G., \& Trematerra, A. (2018). Heating, ventilation, and air condition (HVAC) noise detection in open-plan offices using recursive partitioning. Buildings. 8(12), 169.

Ising, H., \& Kruppa, B. (2004). Health effects caused by noise: evidence in the literature from the past 25 years. Noise \& health, 6(22), 5-13.

Jack, R. E., Sun, W., Delis, I., Garrod, O. G. B., \& Schyns, P. G. (2016). Four not six: Revealing culturally common facial expressions of emotion. Journal of Experimental Psychology: General, 145(6), 708-730.

Jahncke, H., Hygge, S., Halin, N., Green, A. M., \& Dimberg, K. (2011). Open-plan office noise: Cognitive performance and restoration. Journal of Environmental Psychology, 31(4), 373-382.

Jik Lee, P., \& Griffin, M. J. (2013). Combined effect of noise and vibration produced by high-speed trains on annoyance in buildings. The Journal of the Acoustical Society of America, 133(4), 2126-2135. 
Kaarlela-Tuomaala, A., Helenius, R., Keskinen, E., \& Hongisto, V. (2009). Effects of acoustic environment on work in private office rooms and open-plan offices longitudinal study during relocation. Ergonomics, 52(11), 1423-1444.

Kim, J., \& De Dear, R. (2013). Workspace satisfaction: The privacy-communication trade-off in open-plan offices. Journal of Environmental Psychology, 36, 18-26.

Konnikova, M. (2014). The open-office trap. The New Yorker. https://www.newyorker.com/business/currency/the-open-office-trap

Kostallari, K., Parizet, E., Chevret, P., Amato, J-N., \& Galy, E. (2010). Irrelevant speech effect in open plan offices: Comparison of two models explaining the decrease in performance by speech intelligibility and attempt to reduce interindividual differences of the mental workload by task customisation. Applied Acoustics, 161, 107180.

Kristiansen, J. (2010). Is noise exposure in non-industrial work environments associated with increased sickness absence? Noise and Vibration Worldwide, 41(5), 9-16.

Kristiansen, J., Mathiesen, L., Nielsen, P. K., Hansen, Å. M., Shibuya, H., Petersen, H. M., Lund, S. P., Skotte, J., Jørgensen, M. B., \& Søgaard, K. (2009). Stress reactions to cognitively demanding tasks and open-plan office noise. International Archives of Occupational and Environmental Health, 82(5), 631-641. 
Kulke, Louisa \& Feyerabend, Dennis \& Schacht, Annekathrin. (2020). A comparison of the Affectiva iMotions facial expression analysis software with EMG for identifying facial expressions of emotion. Frontiers in Psychology. 11, 329.

Langer, J., Taylour, J., \& Smith, A. P. (2020). Noise exposure, satisfaction with the working environment, and the wellbeing process. ICBEN 2020.

Lamb, S., \& Kwok, K. (2016). A longitudinal investigation of work environment stressors on the performance and wellbeing of office workers. Applied Ergonomics, 52, 104-111.

Lazarus, R. S. 1991. Emotion and adaptation. New York: Oxford University Press.

Lazarus, R. S., \& Folkman, S. (1984). Stress, appraisal, and coping. New York: Springer.

Leaman, A., \& Bordass, B. (1999). Productivity in buildings: the 'killer'variables. Building Research \& Information, 27(1), 4-19.

Lee, Y., Aletta, F. (2019). Acoustical planning for workplace health and well-being: A case study in four open-plan offices. Building Acoustics. 26, 207-220.

Lee, P. J., Lee, B. K., Jeon, J. Y., Zhang, M., \& Kang, J. (2016). Impact of noise on self-rated job satisfaction and health in open-plan offices: a structural equation modelling approach. Ergonomics, 59(2), 222-234.

Lee, Y., Nelson, E.C., Flynn, M.,J., \& Jackman, J., S. (2020). Exploring soundscaping 
options for the cognitive environment in an open-plan office. Building Acoustics, 27, 185202.

Liebl, A., Assfalg, A., \& Schlittmeier, S. J. (2016). The effects of speech intelligibility and temporal-spectral variability on performance and annoyance ratings. Applied Acoustics, $110,170-175$.

Maher, A., \& Von Hippel, C. (2005). Individual differences in employee reactions to openplan offices. Journal of environmental psychology, 25(2), 219-229.

Mayo, L. M., \& Heilig, M. (2019). In the face of stress: Interpreting individual differences in stress-induced facial expressions. Neurobiology of Stress, 10, 100166.

10.1016/j.ynstr.2019.100166

McDuff, D., Karlson, A., Kapoor, A., Roseway, A., \& Czerwinski, M. (2012). AffectAura. Proceedings of the 2012 ACM annual conference on Human Factors in Computing Systems - CHI'12.

Mehta, R., Zhu, R., \& Cheema, A. (2012). Is noise always bad? Exploring the effects of ambient noise on creative cognition. Journal of Consumer Research, 39(4), 784-799.

Muaremi, A., Arnrich, B., \& Tröster, G. (2013). Towards measuring stress with smartphones and wearable devices during workday and sleep. BioNanoScience, 3(2), 172-183. $10.1007 / \mathrm{s} 12668-013-0089-2$ 
Oldham, G. R., \& Rotchford, N. L. (1983). Relationships between office characteristics and employee reactions: A study of the physical environment. Administrative Science Quarterly, 28(4), 542-556.

Pabst, S., Brand, M., \& Wolf, O. T. (2013). Stress and decision making: A few minutes make all the difference. Behavioural Brain Research, 250, 39-45. 10.1016/j.bbr.2013.04.046

Peich, M., Husain, M., \& Bays, P.M. (2013) Age-related decline of precision and binding in visual working memory. Psychology and Aging, 28(3), 729-743.

Pejtersen, J. H., Feveile, H., Christensen, K. B., \& Burr, H. (2011). Sickness absence associated with shared and open-plan offices - a national cross sectional questionnaire survey. Scandinavian Journal of Work, Environment \& Health, 37(5), 376-382.

Perea, M., Panadero, V., Moret-Tatay, C., \& Gómez, P. (2012). The effects of inter-letter spacing in visual-word recognition: Evidence with young normal readers and developmental dyslexics. Learning and Instruction, 22(6), 420-430. 10.1016/j.learninstruc.2012.04.001

Puranik, H., Koopman, J., \& Vough, H. C. (2020). Pardon the interruption: An integrative review and future research agenda for research on work interruptions. Journal of Management, 46(6), 806-842. 
Reeves, J. P., Knight, A. T., Strong, E. A., Heng, V., Neale, C., Cromie, R., \& Vercammen, A. (2019). The application of wearable technology to quantify health and wellbeing: Co-benefits from urban wetlands. Frontiers in Psychology, 10, 1840.

Salame P., Baddeley A. (1982). Disruption of short-term memory by unattended speech: implications for the structure of working memory. J. Verbal Learn. Verbal Behav. 21 150164.

Sander, E. L. J., Caza, A., \& Jordan, P. J. (2019). Psychological perceptions matter: Developing the reactions to the physical work environment scale. Building and Environment, 148, 338-347.

Senan, T. U., Jelfs, S., \& Kohlrausch, A. (2018). Cognitive disruption by noise-vocoded speech stimuli: Effects of spectral variation. The Journal of the Acoustical Society of America, 143(3), 1407-1416.

Schoonbaert, S., \& Grainger, J. (2004). Letter position coding in printed word perception: Effects of repeated and transposed letters. Language and Cognitive Processes, 19(3), 333-367.

Seddigh, A., Berntson, E., Platts, L. G., \& Westerlund, H. (2016). Does personality have a different impact on self-rated distraction, job satisfaction, and job performance in different office types?. PloS one, 11(5), e0155295. 
Smith-Jackson, T. L., \& Klein, K. W. (2009). Open-plan offices: Task performance and mental workload. Journal of environmental Psychology, 29(2), 279-289.

Stapelberg, N., Neumann, D. L., Shum, D., McConnell, H., \& Hamilton-Craig, I. (2018). The sensitivity of 38 heart rate variability measures to the addition of artifact in human and artificial 24-hr cardiac recordings. Annals of Noninvasive Electrocardiology, 23(1), e12483.

Szalma, J. L., \& Hancock, P. A. (2011). Noise effects on human performance: A metaanalytic synthesis. Psychological Bulletin, 137(4), 682-707.

Van De Voorde, K., Paauwe, J., \& Van Veldhoven, M. (2012). Employee well-being and the HRM-organizational performance relationship: a review of quantitative studies. International Journal of Management Reviews, 14(4), 391-407.

Verhaeghen, P., \& Basak, C. (2005). Ageing and switching of the focus of attention in working memory: results from a modified N-back task. The Quarterly journal of experimental psychology. A, Human experimental psychology, 58(1), 134-154.

Verma, J. P. (2015). Repeated Measures Design for Empirical Researchers. John Wiley \& Sons.

Vicario, C. M., Rafal, R. D., Martino, D., \& Avenanti, A. (2017). Core, social and moral disgust are bounded: A review on behavioral and neural bases of repugnance in clinical disorders. Neuroscience and biobehavioral reviews, 80, 185-200. 
Venetjoki, N., Kaarlela-Tuomaala, A., Keskinen, E., \& Hongisto, V. (2006). The effect of speech and speech intelligibility on task performance. Ergonomics, 49(11), 1068-1091.

Vrijkotte, T. G., van Doornen, L. J., \& de Geus, E. J. (2000). Effects of work stress on ambulatory blood pressure, heart rate, and heart rate variability. Hypertension,35(4)880-886. https://doi.org/10.1161/01.hyp.35.4.880

Watson, D., Clark, L. A., \& Tellegen, A. (1988). Development and validation of brief measures of positive and negative affect: The PANAS scales. Journal of Personality and Social Psychology, 54(6), 1063-1070.

Weiss, H. M., \& Cropanzano, R. (1996). Affective events theory: A theoretical discussion of the structure, causes and consequences of affective experiences at work.

Wellens, B.T., \& Smith, A.P. (2006) Combined workplace stressors and their relationship with mood, physiology, and performance, Work \& Stress, 20:3, 245258, DOI: $10.1080 / 02678370601022712$

Węziak-Białowolska, D., Dong, Z., \& McNeely, E. (2018). Turning the Mirror on the Architects: A Study of the Open-Plan Office and Work Behaviors at an Architectural Company. Frontiers in Psychology, 9:2178.

Yan, G., Meng, Z., Liu, N., He, L., \& Paterson, K. B. (2018). Effects of irrelevant background speech on eye movements during reading. Quarterly Journal of Experimental Psychology, 71(6), 1270-1275. 
Yadav, M., Cabrera, D. (2019). Two simultaneous talkers

distract more than one in simulated multi-talker environments,

regardless of overall sound levels typical of open-plan offices.

Applied Acoustics, 148, 46-54.

Zhai, J., \& Barreto, A. (2006). Stress detection in computer users based on digital signal processing of noninvasive physiological variables. Conference proceedings : ... Annual International Conference of the IEEE Engineering in Medicine and Biology Society. IEEE Engineering in Medicine and Biology Society. Annual Conference, 2006, 1355 1358. https://doi.org/10.1109/IEMBS.2006.259421

Zhang, X., Lian, Z., \& Wu, Y. (2017). Human physiological responses to a wooden indoor environment. Physiology \& Behavior, 174, 27-34.

Zohar, D., Tzischinski, O., \& Epstein, R. (2003). Effects of energy availability on immediate and delayed emotional reactions to work events. Journal of Applied Psychology, 88(6), 1082-1093. 